\title{
The Influence of Brand Image Congruence, Relationship Type and Self-Construal on Consumers' Purchase Intention
}

\author{
Shenghong Ye, Guobin $\mathrm{Wu}^{*}$ \\ School of Management, Jinan University, Guangzhou, China \\ Email: "761593977@qq.com
}

Received 20 June 2016; accepted 25 July 2016; published 28 July 2016

Copyright (C) 2016 by authors and Scientific Research Publishing Inc.

This work is licensed under the Creative Commons Attribution International License (CC BY). http://creativecommons.org/licenses/by/4.0/

(c) (i) Open Access

\begin{abstract}
Since ancient times, relation-oriented Chinese people have attached great importance to the philosophy that courtesy calls for reciprocity. However, when choosing gifts, we are always caught in a dilemma: give him what I love, or what he wants. By bringing two variables-relationship type and self-construal into the model studying consumers' gift-giving behavior, this paper aims to find out solutions to the problem above from the perspective of the consistency of brand image's influence on the consumers' purchase intention. The results show that: 1) the brand image congruence and the relationship type have significant reciprocal effect on purchase intention, and 2) the interaction between brand image congruence and self-construal has remarkable impact on purchasing intention.
\end{abstract}

\section{Keywords}

Relationship Types, Communal Relationships, Exchange Relationships, Self-Construal, Brand Image and Gift Givers Congruence, Brand Image and Gift Receivers Congruence

\section{Description of the Problem}

Gift-giving, existing in all developmental phase of every society, enjoys long and profound historical and cultural origins, especially in China where the philosophy "courtesy demands reciprocity" has been advocated since ancient times. Though it is a behavior costing us a large amount of time, energy and money in our daily life [1], gift-giving, as an economic affair and an implicit communication process, plays a dynamic role in interpersonal relationships.

\footnotetext{
"Corresponding author.
}

How to cite this paper: Ye, S.H. and Wu, G.B. (2016) The Influence of Brand Image Congruence, Relationship Type and Self-Construal on Consumers' Purchase Intention. Open Journal of Business and Management, 4, 535-548. 
Interpersonal relationship is a notable feature, and a fundamental variable and decisive factor [2] to achieve marketing success in China, a relationship-oriented society [3]. Firstly, though scholars have realized how interpersonal relationships affect gift-giving behavior, the existing research is confined to theoretical exposition and abstract conceptual model deficient in empirical study. Secondly, despite of the recognition that interpersonal relationship affects Chinese consumers' gift-giving behavior, researches interpreting gift-giving behavior from the perspective of self-construal are still inadequate. Thirdly, most of the existing studies on Chinese consumers' gift-giving behavior are prone to directly discuss and study the global concept of gift-giving behavior rather than split it into clearer and more specific behavioral variables, which hinders related research results providing more guidance for practice.

To Qi Haifeng and Fei Hongping (2011), it is an attractive research topic on studying what kind of brand people would choose under the dual influences of self-judgment and ethics for human relationships [4]. Focusing on consumers' purchasing choices subject to the brand image congruence, this paper aims to analyze the effect and mechanism of action that relationship types, an external environment factor, and self-construal, an internal personality factor, have on the above problem. On the basis of enriching the existing research findings and filling the research gap, this paper also aims at figuring out the influencing factors and mechanism of actions of Chinese consumers' gift-giving behavior to help companies at home and abroad better understand Chinese market and consumers, and provide reference and enlightenment for purposefully carrying out marketing practice.

\section{Literature Review}

Gift-giving refers to a spontaneous and voluntary behavior concerning bestowal and exchange of gifts between the giver and receiver [5]. The research topic of this paper is interpersonal gift-giving (IG), namely gift-giving behavior among individuals.

Researchers in marketing usually carry out their research on gift-giving behavior from the giver's perspective, and focus on motivation of gift-giving. Thus, they conclude that motivation is a key variable determining consumers' gift-giving behavior, and different motivations would result in different gift-giving behaviors [6]. Based on Chinese culture background, related research associates special Chinese cultural values with consumers' gift-giving behavior and concludes that localized values and social norms such as Guanxi [7], Renqing [8], face [9], manners and retribution [10] are essential factors shaping Chinese consumers' unique gift-giving behavior [11]. Thus, the analytical framework of gift-giving behavior and psychology in terms of local Chinese consumers is established.

In terms of consumers' choice on brand image congruence, Morgan and Susan's (2011) research shows that compared with giving gift to an estranged friend, giving a gift inconsistent with the giver's identity and image to a close friend would make the giver feel strong identity threat [12]. On the contrary, when giving a gift to an estranged friend, the giver would not feel identity threat, therefore, it is more likely for he/she to choose product or brand inconsistent with his/her own identity and image to meet the receiver's need or cater to his/her taste. Wolfinbarger and Gilly (1996) classified the context of gift-giving into two kinds: the experienced life rituals and the undergoing life rituals. The research findings show that compared with the experienced life rituals, gift givers in the context of the undergoing life rituals are more prone to choose gifts consistent with their own image [13]. Suri et al. (2015) analyzes how gift-giving context (interpersonal gift-giving and self gift-giving), intention of gift-giving (retribution and compensation) and self-construal (independent self and dependent self) affect consumers' gift-choosing behavior, providing new perspectives and paradigms for better understanding and studying consumers' gift-giving behavior [14]. Compared with foreign scholars, scholars at home have got little results. That is to say, there is still much room to make progress in this field.

\subsection{Relationship and Relationship Type}

Relationship and relationship type. In Chinese language environment, "guanxi” has abundant implications. To Chen and Chen (2004) guanxi is a unique social structure in China as well as an informal and invisible link between two individuals associated by covert psychological contract, aiming at maintaining their role play and social intercourse [15]. In western countries, interpersonal relationship is featured by rationality, transience, and unsustainability, while in China; it is featured by sensibility, stability and sustainability [16].

In relationship research, it is an important method to classify and define interpersonal relationship [17]. By adopting the binary classification method of Clark and Mills (1993) [18], this research classifies the relationship 
types into two kinds: communal relationships and exchange relationships. To the researchers, the above classification is a general summary of all relationship types, which contains all relation forms between gift givers and receivers in the gift-giving process. It has strong operability in carrying out the specific research.

Correlational studies. In the theoretical research of relationship, more and more scholars tend to apply the relationship theory to studying brand marketing of gifts so as to explore the interaction mechanism between relationship and brand marketing of gifts. For example, Wang Haizhong (2012) has testified that in the context of gift-giving, the relationship types (communal relationships and exchange relationships) would have significant regulating effect on the above variables [8]. Foreign scholars have also explored the gift-giving behavior from the perspective of relationship intimacy. For example, Wolfinbarger and Gilly (1996) has empirically studied how relationship intimacy and similarity affect gift givers' choice on brand image congruence from the givers' point of view [13]. Morgan and Susan (2011),carrying out the research from the perspective of the gift giver, has proved that the relationship intimacy has regulating effect on the gift givers' choice of gift consistent or not with their identity, and further interpreted the mechanism of action during the process by taking the identity threat perception as the intervening variable [12]. Gabriele et al, from the perspective the gift receiver, has testified that the relationship intimacy has no regulating effect on the receiver's degree of satisfaction with the gift Whether the receiver is satisfied with the gift or not is only related with the consistency between the gift and the giver's identity and image. That is to say, in any case, the receiver would show high degree of satisfaction to the gift consistent with the giver's identity and image [19].

\subsection{Self-Construal}

Concept. Self-construal, a cognitive structure, reflects how individuals comprehend (through their cognition, attitude, and sense) [20] their relationships with others (related or separated, similar or different). As a vital internal factor [21] resulting in different cognition, emotion, motivation and action, self-construal also plays an important role in guiding and determining an individual's consuming behavior.

Classification and Features. In the classification of the types and dimension of self-construal, Markus and Kitayama's (1991) [20] classification method, categorizing self-construal into independent self and interdependent self is approved and adopted by most correlational research. There are notable differences in the mode of thinking, intention and pattern of action among different subjects of self-construal [22].

People of independent self-construal would evaluate the meaning of their action with reference of their own internal thoughts, capacity, emotion and behavior rather than those of others. On the contrary, people of dependent self-construal would take others' thoughts, emotions and behavior into consideration before they decide their own attitude and behavior. In other words, the demand of others and society would provides important reference and guidance for individuals of dependent self-construal [23].

Correlational studies. Throughout the correlational studies, few of them probe into consumers' brand consumption behavior by associating self-construal with gift-giving phenomenon. There are even fewer studies focusing on the problem whether the consumer would stick to his own taste or give it up to cater to the gift receiver's preference [14]. To Zhang Zhe and Zhang Zhiwei (2013), solutions to the mentioned problem lie in the self-construal of different gift givers [24]. When the fashion identity of givers disagrees with that of receivers, individuals of well developed dependent self-construal would prefer to make choices according to the receivers' fashion identity, showing that they make their purchasing decision by catering to others' liking. It is necessary to conduct research concerning this gift-giving problem from the perspective of self-construal due to limited correlational studies.

\subsection{Brand Image Congruence}

"Brand image congruence", namely self-brand image congruence, refers to consumers' perception consistency and degree of coincidence between the image and personality presented by the brand and those showed by consumers themselves [25].

This paper focuses on consumers' purchasing decision-making in the context of gift-giving. Based on the theory of "self-brand image congruence" and combined with related research experience, this paper classifies brand image congruence into two dimensions, namely "brand image-gift giver congruence" and "brand image-gift receiver congruence", respectively standing for the integrating degree and consistency between the gift giver's self-image and the brand image, and that between the gift receiver's self-image and the brand image. 
Throughout literature review, there are limited documents studying consumers' gift-giving behavior from the perspective of gift giver/receiver's image and the brand image congruence. Related studies are mainly conducted by foreign researchers with inconsistent conclusions. For example, according to Park's (2015) [26] findings, South Koreans show no concern for self image and brand image congruence when purchasing gifts. To Belk and Coon (1993), among couples in passionate love and dating, receivers prefer to have gift consistent with image of givers [27]. However, research findings of Morgan and Susan (2011) shows that in the context of gift-giving, it is likely for the consumers to choosing gifts inconsistent with their own image but consistent with the gift receivers' image to meet the demand of receivers or cater to their tastes [12].

\section{Assumption Deductions and Research Model}

\subsection{Relationship Type and Brand Image Congruence Have Reciprocal Effect on Purchasing Intention}

China is a relationship-oriented society where relationship plays a subtle but vital role in people's daily communication [28]. In China, one's position in the network of relationship is often emphasized. It is agreed that different attitude and behavior should be adopted in response to different objects [29]. Joy and Annamma (2001) find that consumers' gift-giving behavior differs in the form of continuous sequence when they present gifts to people of different degree of intimacy [30]. According to Jiang Lianxiong's (2007) empirical research on Chinese consumers' decision-making style of purchasing gifts, it is testified that relationship type has decisive effect on Chinese consumers' decision-making style of purchasing gifts [11]. It means that different relationship types do have different guiding function for making the purchasing decision. The study confirms the relationship type is an important segmentation variable in China's gift market [12]. He Jiaxun and Lu Taihong (2007) also point out that consumers' response to the brand activities would be regulated by the relationship type [31]. Wang Haizhong empirically studies the claim, and find out that relationship type has significant regulatory effect on the relationship between luxury brand identity significant degree and consumers' brand purchasing intention [8]. To sum up, assumptions as follows are put forward.

Hypothesis 1: Interaction of Relationship type and brand image congruence affects consumers' purchasing intention for brand of gifts.

This paper further classifies relationship types into two kinds: communal relationship and exchange relationship by adopting Clark and Mills's (1993) [18] classification method. In communal relationship, two sides have great affection to each other and one does everything for the other out of his/her inner sincere concern but asks for nothing equal in return. It can be understood as an intimate relationship. In exchange relationship, two sides have no strong affection to each other, and their interaction is based on exchange for equal benefits in return. It can be understood as estranged relationship. Aron and his partners (1993) point out that gift giver often choose a gift out of his/her own preference when presenting it to an intimate friend [32]. Bonney and his partners (2010) also believe that the gift giver would prefer to choose what he/she likes as a gift when presenting it to an intimate friend, because it can better show the giver's sincerity and self-conception [33]. Meanwhile, Morgan and Susan (2011) state that in the context of gift-giving, it is likely for consumers to choose brand image inconsistent with their own image but consistent with receivers' images to satisfy receivers' demand or cater to their tastes [12]. Though they come up with this view point, they never carry out further exploration to testify this possibility. Fortunately, Francesca and Francis's (2011) research fills the gap [1]. It shows that when presenting gifts for estranged friends, givers usually comply with the tastes of receivers, adhering to receivers' image congruence. Therefore, on the basis of the assumption H1, they further put forward the following assumption.

Hypothesis 1a: For gift-giving behavior in exchange relationship, compared with gifts consistent with the giver's image, the giver prefers to purchase gifts consistent with the receiver's image.

Hypothesis 1b: For gift-giving behavior in communal relationship, compared with gifts consistent with the receiver's image, the giver prefers to purchase gifts consistent with his own image.

\subsection{Self-Construal and Brand Image Congruence Have Reciprocal Effect on Purchasing Intention}

Self-construal plays an important role in determining and guiding the consuming behavior, with no exception for gift-giving behavior. Individuals of independent self have strong self-consciousness. They pay more attention to 
their own thoughts and feelings, and they are not sensitive to others' demands and influence. Individuals of dependent self value their relationships with others and attach importance to positive evaluations others give for them. So they are more willing to think about questions from others' perspectives, and more easily influenced by others [34]. They prefer to adjust their own behavior in line with others' demands [20]. Torelli's (2006) research also indicates that compared with individuals of independent self, individuals of dependent self are more willing to abide by others' view and social norms [35]. Individuals of independent self emphasize differences and keep a distance away from others, showing low level of assimilation.

Zhang Zhe and Zhang Zhiwei's (2013) research indicates that gift givers' choice of brand depends on to what degree they stick to their own tastes or follow others' preference [24]. At that time, self-construal of gift givers has remarkable regulatory effect. Research conducted by Suri et al. shows that individuals of independent self have higher purchasing intention for gifts showing self-conception and strengthening self-image, while individuals of dependent self have lower purchasing intention for those gifts because they would constrain their own expectation and needs and pay more attention to others' or collective interest [14]. Zhang Yuanxiong (2011) also points out the following phenomena. Individuals of independent self emphasize expression of their own feelings when presenting gifts and they tend to show real selves when giving gifts [36]. Individuals of dependent self, deindividualized to a great extent, merge with group members, so they care more about others' preference when giving gifts. Based on the above analysis, the following assumptions are put forward.

Hypothesis 2: Interaction between self-construal and brand image congruence affects consumers' purchasing intention of brand for gifts.

Hypotheisi 2a: Compared with brands consistent with the givers' images, people of dependent self have higher purchasing intention for gifts consistent with receivers' images.

Hypothesis 2b: Compared with brands consistent with the receivers' images, people of independent self have higher purchasing intention for gifts consistent with givers' images.

Based on the above analysis, a research model as Figure 1 is established.

\section{Research one: Consistency of brand image and the interactivity of relation type.}

\section{Preparation}

Consistency of brand image. In terms of the selection of manipulation material, this paper follows the research method and thinking of Cao Yin and Fu Guoqun (2012) [37], replacing the "consistency of brand image" with that of "user's image". A distinguish of the consistency between the gift-giver and the recipient can be made through deciding "whether the two are the users of the brand", which is where the consistency depends on. In terms of the selection of inspection scale, this paper adopts the "stannic scale" with three items in Gabriele et al.'s (2015) [19] research and refers the design method and thinking of Zhang Zhe and Zhang Zhiwei (2013)

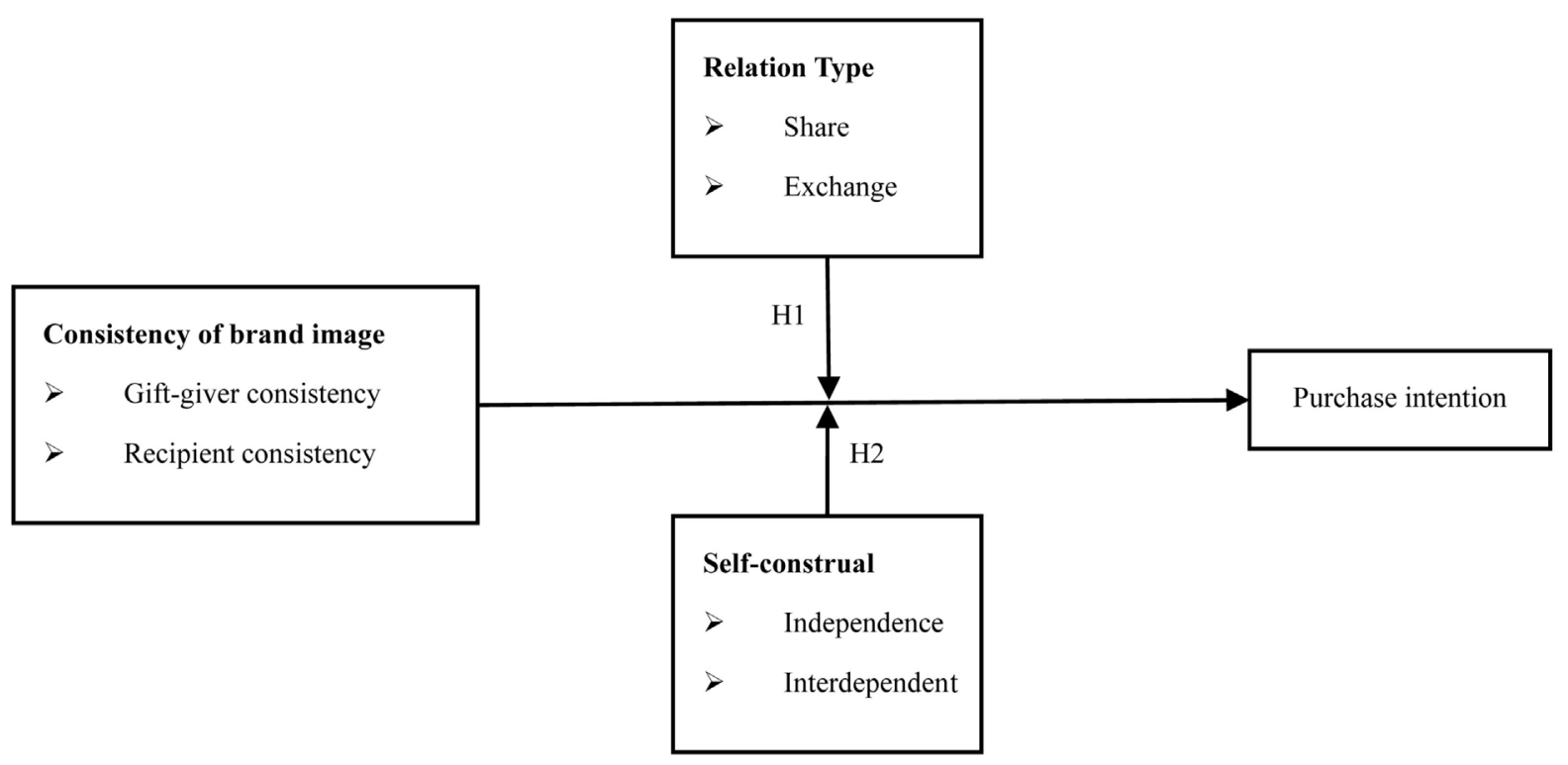


[24] and Gabriele et al. (2015) [19] in dealing with the gift choice tendency. The lower the scale is, the more consistency is between the brand image and the gift-giver, and vice versa.

Relation type. This paper intends to employ the classification method of Clark and Mills (1993) to divide the relation type into shared relation and exchanged relation [18]. In light of the definition and examples of the two relation types proposed by Clark and Mills, the constitutional dimensions classified by Zhang Chuang, Zhuang Guijun (2012) [38] and Zhuang et al. (2010) [2] as well as the personal relationship quality scale put forward by Dong and Zhuang (2013) [39], the stitutional materials used in manipulating the relation type in this research are collected after adapting the materials in the research of Agarwal (2005) [40], Francesca and Francis (2011) [1], and Wang Haizhong (2012) [8].

When inspecting the manipulation of the relation type, this paper intends to adopt "intimacy" to measure whether the understanding and the perception of the testee on exchanged and shared relation type are correct or not. With the methods used in the scholar Morgan and Susan (2011)'s [12] research, this paper helps the testees to make evaluations about the relationship intimacy between the recipients and themselves: "1" for "far from close" and "7" for "very close".

Purchase intention. As for the measurement of the "purchase intention", this paper employs the seventh-grade Likert scale which was used by Dodds (1991) [41]. (Testees are asked to make their scores according to the real situation: "1" for "strongly disagree", "4" for "keep neutrality" and "7" for "Totally agree".) In light of the research purpose, four scale items are finally determined after slight adjustment of the expressions in the original scale and the selection of the related items.

\section{Design and Steps}

This paper mainly adopts the method of " $2 * 2$ between-group design". (the former "2" refers to consistency of the brand image: of the gift-giver and of the recipient); the latter refers to the relation type: the shared and the exchanged). This paper chooses to manipulate the relation type through "object recalling" method, in which environment factors are of little importance for the manipulation results. In light of this, online questionnaire (Questionnaire Web, www.wenjuan.com) is chosen with 10 RMB for the testees as the reward.

The steps are as following: first of all, testees should fill in the four blanks with personal basic information, including gender, age, education background and profession; next, ask testee to read the introduction material of the shared and the exchanged relations and recall the suitable objects. In order to set the questionnaire in a real situation, testee must write down the family name and gender of his reference objects, and make evaluations on the relationship between his relation object and himself; then, read the introduction material about gift-giving situation and manipulation material about consistency of brand image, on which evaluations should also be made; finally, finish the questionnaire with testee's purchase intention.

\section{Data Processing}

Description of the statistic analysis. During this research, 170 questionnaires are issued. Excluding the 9 incomplete ones, there are 161 questionnaires valid for analysis with a returning rate of $94.7 \%$. Most of the testees are working male or students from 24 to 41 with an undergraduate education background. The overall sample distribution is normal. The specific data is showed in the following Table 1.

Valid reliability analysis. According to the analysis results in Table 2, the Cronbach's a coefficient value of brand image consistency and purchase intention are 0.938 and 0.915 (above 0.9) and the CITC of each item is over 0.7 , which depicts sound scale reliability.

The KMO of brand image consistency scale is 0.755 , and the index value of Bartlett's test of sphericity is $426.182, p=0.000<0.001$; One factor is extracted with accumulated variance contribution rate of $88.917 \%$. The KMO of purchase intention scale is 0.848 , the index value of Bartlett's test of sphericity 442.416, $\mathrm{p}=0.000$ $<0.001$; One factor is extracted with accumulated variance contribution rate of $79.632 \%$. Moreover, validities of the two scales are sound.

Manipulation check. The manipulation check on relation type is completed through the relation intimacy index. The data processing result depicts that the shared relation group $\left(\mathrm{M}_{\text {shared }}=5.31\right)$ earns higher score compared with the exchanged group $\left.\left(\mathrm{M}_{\text {exchanged }}=4.79\right), \mathrm{t}=2.411, \mathrm{p}=0.017<0.05\right)$, which means a success in group manipulating of the relation type. The giver-congruence $\left(\mathrm{M}_{\text {giver-congruence }}=2.42\right)$ earns lower score compared with the receiver-congruence $\left(\mathrm{M}_{\text {receiver-congruence }}=6.58, \mathrm{t}=-18.133, \mathrm{p}=0.000<0.001\right)$ on the consistency of brand image, which also means a success in manipulating the consistency of brand image.

Hypothesis testing. This paper chooses MANOVA (Multivariate Analysis of Variance) to test the interaction effect that consistency of brand image and relation type make on purchase intention. First of all, a test is made to 
Table 1. Result description of the statistic analysis.

\begin{tabular}{|c|c|c|}
\hline Features of sample & Frequency & Percentage \\
\hline \multicolumn{3}{|c|}{ Gender } \\
\hline Male & 101 & 62.7 \\
\hline Female & 60 & 37.3 \\
\hline \multicolumn{3}{|c|}{ Age } \\
\hline $18-23$ & 5 & 3.1 \\
\hline $24-29$ & 33 & 20.5 \\
\hline $30-35$ & 57 & 35.4 \\
\hline $36-41$ & 43 & 26.7 \\
\hline $42-47$ & 13 & 8.1 \\
\hline Above 48 & 10 & 6.2 \\
\hline \multicolumn{3}{|c|}{ Education Background } \\
\hline Diploma or below & 15 & 9.3 \\
\hline Undergraduate & 125 & 77.6 \\
\hline Postgraduate or above & 21 & 13.0 \\
\hline \multicolumn{3}{|c|}{ Profession } \\
\hline Student & 25 & 15.5 \\
\hline Working people & 126 & 78.3 \\
\hline Freelance worker & 10 & 6.2 \\
\hline Total & 161 & 100.0 \\
\hline
\end{tabular}

Table 2. Results of reliability analysis.

\begin{tabular}{cccc}
\hline Variant & Item code & Initial CITC & Cronbach's Alpha \\
\hline \multirow{2}{*}{ Consistency of brand image } & Q8_1 & 0.897 & 0.938 \\
Purchase intention & Q8_2 & 0.836 & 0.880 \\
& Q8_3 & 0.838 & 0.915 \\
\hline
\end{tabular}

detect the homoscedasticity. It turns out that the variance difference is not obvious $(\mathrm{F}=0.743, \mathrm{p}=0.528>0.05)$. Therefore, the homoscedasticity can be well testified and the interactive effect can be detected. The testing results are in Table 3: the main effect of relation type and consistency of brand image on purchase intention is not obvious $\left(\mathrm{F}_{\text {relation type }}=0.076, \mathrm{p}_{\text {relation type }}=0.783>0.05, \mathrm{~F}_{\text {consistency of brand image }}=2.678, \mathrm{p}_{\text {consistency of brand image }}=0.104>\right.$ $0.05)$, while the interactive effect of relation type and consistency of brand image on purchase intention is quite obvious $(\mathrm{F}=96.525, \mathrm{p}=0.000<0.001)$, In light of this, $\mathrm{H} 1$ is verified.

On the basis of an obvious interactive effect, further simple effect analysis also needs to be made to detect whether the average value of each group is obvious or not. The result shows that testees are more likely to purchase the brand that matches the identity of the gift-giver $\left(\mathrm{M}_{\text {giver-congruence }}=5.25\right)$ rather than that of the recipient 
Table 3. Results of variance analysis.

\begin{tabular}{ccccccc}
\hline & Dependent variant: purchase intention & & & \\
\hline Source & III type quadratic sum & df & Mean square & F & Sig. \\
\hline Relation type & 0.105 & 1 & 0.105 & 0.076 & 0.783 \\
Consistency of brand image & 3.682 & 1 & 3.682 & 2.678 & 0.104 \\
Relation type and consistency of brand image & 132.684 & 1 & 132.684 & 96.525 & 0.000 \\
Deviation & 215.813 & 157 & 1.375 & & & \\
Total & 3339.063 & 161 & & & \\
\hline
\end{tabular}

$\left(\mathrm{M}_{\text {receiver-congruence }}=2.97, \mathrm{~F}=63.608, \mathrm{p}=0.000<0.001\right)$ when giving gifts to those who have shared relation with them. Table 4 and Figure 2 can clearly demonstrate the salient average value. The above analysis indicates that consumers are more likely to choose the brand that matches their own identity when giving gifts to those who have shared relation with them. On the contrary, they intend to choose the brand that matches the recipient identity when the recipient shares exchanged relation with them. Here, H1a and $\mathrm{H} 1 \mathrm{~b}$ are also verified.

\section{Research Two: Interaction between Consistency of Brand Image and Self-construal}

\section{Preparation}

In the second research, methods and tools used in the previous research are also adopted in dealing with the two variables: consistency of brand image and purchase intention. Manipulation check is employed in self-construal through the method of circling personal pronoun. The reading materials are two paragraphs of travel memory which is adapted after referring to related researches of Chinese scholar's. There are 21 personal pronouns in each paragraph; the only difference between the two paragraphs is the different person reference, such as "I" or "we". In light of Chai Junwu's (2011) method of testing the manipulation effect [42], the research employs Aaker and Lee's (2001) seven points scale of six items [43]. The former three are applied to measure the degree of being self-centered, the latter three to measure the degree of focusing on others.

\section{Design and Steps}

This paper mainly adopts the method of " $2 * 2$ between-group design". The former two refer to the consistency of brand image: giver-congruence and receiver-congruence; the latter two refer to self-construal: independent self and interdependent self. Self-construal, as a variable in psychology, requires an environment of high quality if it wants to deliver an effective manipulation result. In consideration of the quiet environment of the library which can ensure the effectiveness and the persistence of the manipulation results, this research is carried out in the library of JNU.

The steps taken are as follows: first, make a brief introduction about the research background to the testees and randomly cut them into four groups after answering their questions, ensuring them to do the questionnaire independently; second, ask the testees to fill in the blanks with personal basic information, including gender, age, education background and profession; Third, ask the testees to read the manipulation materials with regard to independent self and interdependent self, ask them to circle all the personal pronouns and to fill in the manipulation check scale; fourth, ask testees to read the introduction material of the gift-giver situation and the manipulation material of the brand image consistency, on which evaluation also requires to be made; finally, finish the questionnaire with purchase intention.

\section{Data Processing}

Description of the statistic analysis. During this research, 148 questionnaires are issued. Excluding the 10 incomplete ones, there are 138 questionnaires valid for analysis with a returning rate of $93.2 \%$. The gender distribution of testees is in balance and most of them are people (most are students) at 18 to 29 with undergraduate and postgraduate education background. The overall sample distribution is normal. The specific data is showed in the following Table 5.

Reliability and validity analysis. Table 6 shows that the Cronbach's a coefficient values of brand image consistency scale and of two self-construal subscale are $0.953,0.941$ and 0.913 (above 0.9), and the Cronbach's a coefficient value of purchase intention is 0.896 (above 0.8 ). The CITC of each measurement item is above 0.7 . The scale validity is sound. 
Table 4. Average value.

\begin{tabular}{ccc}
\hline Relation type & Consistency of brand image & Purchase intention M (SD) \\
\hline \multirow{2}{*}{ Shared relationship } & Giver-congruence & $5.25(1.29)$ \\
& Receiver-congruence & $2.97(1.22)$ \\
Exchanged relationship & Giver-congruence & $3.24(1.28)$ \\
& Receiver-congruence & $4.87(1.02)$ \\
\hline
\end{tabular}

Table 5. Result description of the statistic analysis.

\begin{tabular}{|c|c|c|}
\hline Sample feature & Frequency & Percentage \\
\hline \multicolumn{3}{|c|}{ Gender } \\
\hline Male & 60 & 43.5 \\
\hline Female & 78 & 56.5 \\
\hline \multicolumn{3}{|c|}{ Age } \\
\hline $18-23$ & 94 & 68.1 \\
\hline $24-29$ & 42 & 30.4 \\
\hline $30-35$ & 2 & 1.4 \\
\hline \multicolumn{3}{|c|}{ Education background } \\
\hline Diploma or below & 4 & 2.9 \\
\hline Undergraduate & 93 & 67.4 \\
\hline Postgraduate of above & 41 & 29.7 \\
\hline \multicolumn{3}{|c|}{ Profession } \\
\hline Students & 133 & 96.4 \\
\hline Working people & 5 & 3.6 \\
\hline Total & 138 & 100.0 \\
\hline
\end{tabular}

Table 6. Results of the valid analysis.

\begin{tabular}{|c|c|c|c|}
\hline Variable & Item code & Initial CITC & Cronbach's Alpha \\
\hline \multirow{3}{*}{ Dependent self } & Q1 & 0.866 & \multirow{3}{*}{0.941} \\
\hline & Q2 & 0.889 & \\
\hline & Q3 & 0.876 & \\
\hline Sent-consirual & Q4 & 0.780 & \multirow{3}{*}{0.913} \\
\hline \multirow[t]{2}{*}{ Interdependent self } & Q5 & 0.877 & \\
\hline & Q6 & 0.817 & \\
\hline \multirow{4}{*}{ Purchase intention } & G1 & 0.767 & \multirow{4}{*}{0.896} \\
\hline & G2 & 0.779 & \\
\hline & G3 & 0.797 & \\
\hline & G4 & 0.737 & \\
\hline \multirow{3}{*}{ Consistency of brand image } & $\mathrm{P} 1$ & 0.883 & \multirow{3}{*}{0.953} \\
\hline & $\mathrm{P} 2$ & 0.940 & \\
\hline & P3 & 0.886 & \\
\hline
\end{tabular}




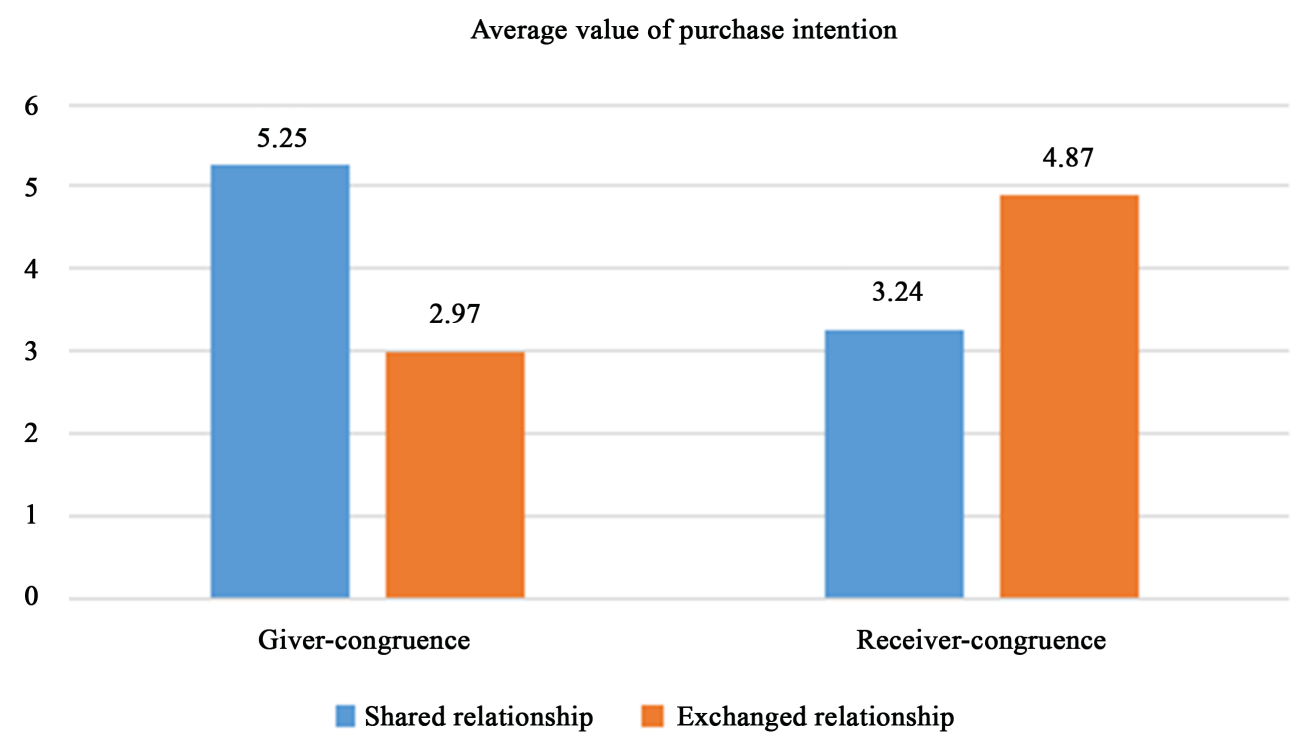

Figure 2. Average value of purchase intention.

The KMO of self-construal scale is 0.787 , and the index value of Bartlett's test of sphericity is $708.515, \mathrm{p}=$ $0.000<0.001$; only two factors are extracted with accumulated variance contribution rate of $87.719 \%$. The $\mathrm{KMO}$ of brand image consistency scale is 0.739 with the index value of Bartlett's test of sphericity $446.636, \mathrm{p}=$ $0.000<0.001$; One factor is extracted with accumulated variance contribution rate of $91.632 \%$. The KMO of purchase intention scale is 0.817 with the index value of Bartlett's test of sphericity $329.875, p=0.000<0.001$; only one factor is extracted with accumulated variance contribution rate of $76.314 \%$. The validities of the above three variables are sound, thus the data analysis of the next step can be implemented.

Manipulation Check. The data resulting from manipulation check on self-construal shows that testees from independent group focus more on themselves $\left(\mathrm{M}_{\text {self }}=4.66\right)$ rather than on others $\left(\mathrm{M}_{\text {others }}=2.93, \mathrm{t}=6.825, \mathrm{p}=\right.$ $0.000<0.001)$; while testees from interdependent group focus more on others $\left(\mathrm{M}_{\text {self }}=2.90, \mathrm{M}_{\text {others }}=4.34, \mathrm{t}=\right.$ $-6.265, \mathrm{p}=0.000<0.001)$. This data results depict a success in the grouping manipulation on self-construal.

The score that the giver-congruence group gets $\left(\mathrm{M}_{\text {giver-congruence }}=2.24\right)$ from brand image consistency is much more lower than the score the receiver-congruence gets. $\left(\mathrm{M}_{\text {receiver-congruence }}=7.54, t=-19.532, \mathrm{p}=0.000<\right.$ 0.001). This also shows the success in manipulating brand image consistency.

Hypothesis Testing. This paper chooses MANOVA (Multivariate Analysis of Variance)to test the interaction effect that self-construal and consistency of brand image make on purchase intention. A test is made to detect the homoscedasticity. It turns out that the variance difference is not obvious $(\mathrm{F}=1.188, \mathrm{p}=0.317>0.05)$. Therefore, the homoscedasticity can be well testified and the interactive effect can be detected. The testing results are in Table 7: The main effect of brand image consistency and self-construal on purchase intention is not obvious $\left(\mathrm{F}_{\text {relation type }}=0.102, \mathrm{p}_{\text {relation type }}=0.750>0.05 ; \mathrm{F}_{\text {consistency of brand image }}=0.477, \mathrm{p}_{\text {consistency of brand image }}=0.491>0.05\right)$, while the interactive effect of brand image consistency and self-construal on purchase intention is quite obvious $(\mathrm{F}=96.525, \mathrm{p}=0.000<0.001)$. In light of this, $\mathrm{H} 1$ is verified.

Similarly, on the basis of an obvious interactive effect, further simple effect analysis also needs to be made to detect whether the average value of each group is obvious or not. The result shows that independent testees are more likely to purchase the brand that matches the identity of the gift-giver $\left(\mathrm{M}_{\text {giver-congruence }}=4.64\right)$ rather than that of the recipient $\left(\mathrm{M}_{\text {receiver-congruence }}=3.59, \mathrm{~F}=18.409, \mathrm{p}=0.000<0.001\right)$; while interdependent testees are more likely to purchase the brand that matches the identity of the recipient $\left(\mathrm{M}_{\text {receiver-congruence }}=4.71\right)$ rather than that of the gift-giver $\left(\mathrm{M}_{\text {giver-congruence }}=3.80, \mathrm{~F}=7.181, \mathrm{p}=0.009<0.05\right)$. Table 8 and Figure 3 can clearly demonstrate the salient average value. The above analysis demonstrates that independent gift-giver is more likely to choose the brand that matches their own indentity when selecting gifts. On the contrary, interdependent gift-giver intends to choose the brand that matches the recipient identity. Therefore, H1a and H1b are also verified. Till now, the hypothesis testing is successfully finished. 
Average value of purchase intention

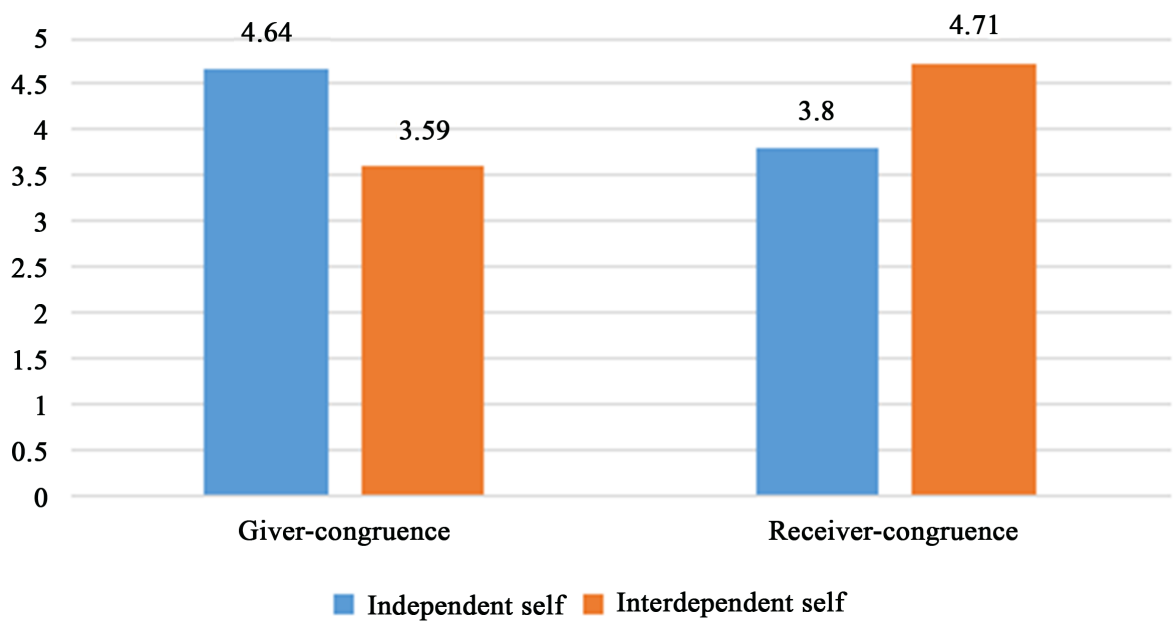

Figure 3. Average value of purchase intention.

Table 7. Result of variance analysis.

\begin{tabular}{ccccccc}
\hline & Dependent variable: purchase intention & & & \\
\hline Source & III type quadratic sum & df & Mean square & F & Sig. \\
\hline Self-construal & 0.707 & 1 & 0.707 & 0.477 & 0.491 \\
Consistency of brand image & 0.152 & 1 & 0.152 & 0.102 & 0.750 \\
Self-construal and consistency of brand image & 33.265 & 1 & 33.265 & 22.412 & 0.000 \\
Deviation & 198.889 & 134 & 1.484 & & \\
Total & 2651.938 & 138 & & & \\
\hline
\end{tabular}

Table 8. Average value.

\begin{tabular}{ccc}
\hline Relation type & Consistency of brand image & Purchase intention M (SD) \\
\hline Independent self & Giver-congruence & $4.64(0.76)$ \\
& Receiver-congruence & $3.59(1.27)$ \\
Interdependent self & Giver-congruence & $3.80(1.28)$ \\
& Receiver-congruence & $4.71(1.49)$ \\
\hline
\end{tabular}

\section{Discussion and Conclusions}

This paper incorporates the relation type and self-construal into the research model of Chinese consumer's giftgiving behavior and makes a discussion about Chinese consumer's purchase intention on brand image consistency and its inside and outside motivation.

The interaction effect between relation type and brand image consistency makes great impact on consumer's purchase intention. In order to express his intention of "to share what I love", the gift-giver is more likely to choose the brand that matches his own identity when the recipient has shared relation with him; while with the intention of "to give what you love", the gift-giver is more likely to choose the brand that matches the recipient identity if the recipient shared a exchanged relation with him.

Meanwhile, the interaction effect between self-construal and brand image consistency makes great impact on consumer's purchase intention on brand. With an intention of "giving what you love", interdependent self would choose the brand in accordance with the recipient identity; while with an intention of "sharing what I love", in- 
dependent self would choose the brand that matches their own identity.

With regard to this conclusion, we can explain it from the aspects of "self-cognition" and "identity threat". First of all, as far as self-cognition is concerned, according to the paper analyzed above, the independent self and interdependent self are two kinds of self-construction individuals, the approaches of gaining self-cognition are different between them. Independent self satisfy their satisfaction by showing their unique personalities fully to intensify self-cognition. However, the interdependent only can satisfy themselves by gaining the affirmation and identification from others to realize self-cognition. So when they choose to pick up presents, the former intensifies self-cognition by presenting something they like to express their tastes and characters. The latter completes their self-cognition to obtain the affirmation and identification from others. It's not difficult to understand why people make this decision by catering to people's likes. Secondly, as for identity threat, blending in and belonging to the relationship of interpersonal circle that is harmonious harmony and submitting to corresponding role obligation and social norms as a member of a group are main ways to acquire their identities and roles for the interdependent. Once their interpersonal relationship appears contradictions and breakages or they are excluded from it because of their maverick and out of place behaviors. The identities and roles of the interdependent will face a big challenge and then they will have a strong sense of identity threat and insecurity. To avoid this kind of adventure, the interdependent will choose a conservative way to go and have the same choice with others so that they will choose gifts by catering to people's likes. On the contrary, the independent care themselves, they are not sensitive about social situations and opinions and influences of others. They just listen to the voice within themselves. Expressing yourself truly and realize your own value are the correct manners to have self-worth and ID authentication. Abandoning style yourself, hobbies and thoughts to cater for people's likes or to have the same ideas with others are big challenges of identity shock and threat for the independent. To avoid this kind of identity threat, they will obey their inner voice and not be influenced by other people's hobbies. They will not depress their own thoughts and personalities deliberately to cater to others. Hence, they will show their inner choices when they face the situation that they need to pick over gifts.

To some extent, this conclusion have confirmed some conclusions of scholars such as Singelis [34] (1994), Markus and Kitayama [20] (1991) about the summaries of the independence and interdependence's features. At the same time, it is the same strain of Zhang Zhe and Zhang Zhi Wei's (2013) [24] research conclusions. It has successfully explained the consumer's behaviors about giving a present to others from the aspect of self-construal theory and its influencing mechanism.

\section{Enlightenment on Marketing}

The research result of this paper firstly demonstrates that consumers would propose different requirements to brand image consistency according to recipient of different relation types. Therefore, enterprises in gift industry can carry out differential marketing strategy and make market segmentation from the perspective of "relation type" so as to cater consumer's physiological activity, purpose and intention when choosing brand for recipient of different relation types. Another significance of this research is that with a correct brand positioning, the gift brand can motivate consumers to establish their own types of self-construal, attracting consumer's interests and improving market share.

\section{Innovations and Prospect}

This paper makes a trial research on the purchase problem - "with whom the brand image should be consistent?" It is a pioneer work compared with the previous research thought which is from the perspective of the gift-giver and the recipient. This paper expounds on the impact that consumer's self-construal makes on the purchase intention of the brand image consistency through empirical research, drawing a clear demarcation on the purchase intention of consumers respectively with independent self and interdependent self and giving innovative discussion on researches about gift-giving.

In consideration of the different gift-giving behaviors due to different situations, this research makes a fixed gift-giving situation, which limits the applicability of this research. Since relation is a complicated variable, this paper chooses an idealized double-dimensional classification method, from which two types of relations are classified without practical significance. Therefore, more scientific classification methods need to be put forward to guide practical operation. 


\section{Funding}

This research was supported by: Key Program of Natural Science in Guangdong-Research on International Development Strategy of Brand in Service Industry (2014A030311022); The Research Project of Jinan University: The Central University Special Funding for Basic Scientific Research Business Expenses (15JNLH005); Jinan University's Scientific Research Creativeness Cultivation Project for Outstanding Undergraduates Recommended for Postgraduate Study.

\section{References}

[1] Francesca, F. (2011) Give Them What They Want: The Benefits of Explicitness in Gift Exchange. Journal of Experimental Social Psychology, 47, 915-922. http://dx.doi.org/10.1016/j.jesp.2011.03.015

[2] Zhuang, G.J. (2012) Relation in Chinese Culture: From the Perspective of Administration Scholar. Modern Economic Science, 34, 18-29.

[3] Peng, Q., Zhuang, G.J. and Zhou, Y. (2012) The Impact of Personal Relationship on Salespersons' Behavior DecisionMaking of Gray Marketing: The Moderating Role of Timing. Forecasting, 31, 8-13.

[4] Qi, H.F. and Fei, H.P. (2011) The Research on the Impact of Consumer Susceptibility to Role-Normative Influence on Chinese's Decision Intension to Unique Brands: Taking Public Roles for Example. Economic Management, 33, 84-94.

[5] Sherry Jr., J.F. (1983) Gift Giving in Anthropological Perspective. Journal of Consumer Research, 10, 157-168. http://dx.doi.org/10.1086/208956

[6] Teigen, K.H., Olsen, M.V.G. and Solås, O.E. (2005) Giver-Receiver Asymmetries in Gift Preferences. British Journal of Social Psychology, 44, 125-144. http://dx.doi.org/10.1348/014466604X23428

[7] Le, J. (2006) On the Model of City Dwellers' Gift-Exchange and Characteristics during the Period of Social Transformation in China. Journal of Jiangxi Normal University (Social Science), 39, 52-57.

[8] Wang, H.Z., Qin, S. and Liu, D. (2012) Decision-Making for Brand Prominence for Luxury Good: High Profile or Low Profile. China Industry Economics, 11, 148-160.

[9] Wang, Q., Razzaque, M.A. and Keng, K.A. (2007) Chinese Cultural Values and Gift-Giving Behavior. Journal of Consumer Marketing, 24, 214-228. http://dx.doi.org/10.1108/07363760710756002

[10] Chan, A.K.K., Denton, L. and Tsang, A.S.L. (2003) The Art of Gift Giving in China. Business Horizons, 46, 47-52. http://dx.doi.org/10.1016/S0007-6813(03)00051-X

[11] Jiang, L.X., Lu, T.H. and Zhou, L. (2007) Chinese Consumer's Decision-Making for Gift Purchase: Relational Orientation or Motivation-driven. Journal of Sun Yat-sen University (Social Science), 5, 117-128.

[12] Ward, M.K. and Broniarczyk, S.M. (2011) It's Not Me, It's You: How Gift Giving Creates Giver Identity Threat as a Function of Social Closeness. Journal of Consumer Research, 38, 164-181. http://dx.doi.org/10.1086/658166

[13] Wolfinbarger, G. (1996) An Experimental Investigation of Self-Symbolism in Gifts. Advances in Consumer Research, 23, 458-462.

[14] Suri, W., Stephen, G. and Cindy, B.R. (2015) Impact of Giving on Self-Construal and Impact of Self-Construal on Giving. Psychology and Marketing, 32, 1-14.

[15] Chen, X.P. and Chen, C. (2004) On the Intricacies of the Chinese Guan Xi: A Process Model of Guan Xi Development. Asia Pacific Journal of Management, 21, 305-324.

[16] Zhou, N., Zhou, Y.Y. and Wang, D.W. (2011) How Consumer Reciprocate Gifts in China? From the Perspective of Recipient. Luojia Management Review, 2, 1-11.

[17] Ho, D.Y.F. and Chiu, C.-Y. (1998) Collective Representations as a Metaconstruct: An Analysis Based on Methodological Relationalism. Culture and Psychology, 4, 349-369. http://dx.doi.org/10.1177/1354067X9800400304

[18] Clark, M. (1993) The Difference between Communal and Exchange Relationships: What It Is and Is Not. Personality and Social Psychology Bulletin, 19, 684-691. http://dx.doi.org/10.1177/0146167293196003

[19] Gabriele, P., Straeter, L. and de Hooge, I. (2014) Give Me Your Self: Gifts Are Liked More When They Match the Giver's Characteristics. Journal of Consumer Psychology, 42, 631-632.

[20] Markus, H.R. and Kitayama, S. (1991) Culture and the Self-Construal: Implication for Cognition, Emotion, and Motivation. Psychlogical Review, 98, 224-225. http://dx.doi.org/10.1037/0033-295X.98.2.224

[21] Zhang, Z. and Zhang, Z.W. (2013) The Effect of Self-Construal on Perference for Brand Prominence in the Context of Gift-Giving. Journal of FuDan University (Social Science), 52, 152-159.

[22] Yao, Q., Chen, R. and Zhao, P. (2011) The Influence of Self-Construals on the Imagery Advertising Strategy. Acta Psychologica Sinica, 43, 674-683. 
[23] Zhou, L. and Jiang, L. (2014) The Influence of Self-Construals on Subjective Well-Being: Empirical Research on Mediating Role of Self-Efficacy and Relationship Harmony. Studies of Psychology and Behavior, 12, 107-114.

[24] Zhang, Z. and Zhang, Z.W. (2013) The Effect of Self-Construal on Preference for Brand Prominence in the Context of Gift-Giving. Journal of FuDan University (Social Science), 52, 152-159.

[25] Sirgy, M.J. (1982) Self-Concept in Consumer Behavior: A Critical Review. Journal of Consumer Research, 9, 287300. http://dx.doi.org/10.1086/208924

[26] Park, S.Y. (1998) A Comparison of Korean and American Gift-Giving Behaviors. Psychology \& Marketing, 15, 577593. http://dx.doi.org/10.1002/(SICI)1520-6793(199809)15:6<577::AID-MAR6>3.0.CO;2-3

[27] Belk, R.W. and Coon, G.S. (1993) Gift Giving as Agapic Love: An Alternative to the Exchange Paradigm Based on Dating Experiences. Journal of Consumer Research, 20, 393-417. http://dx.doi.org/10.1086/209357

[28] Zhuang, G., Xi, Y. and Tsang, A.S.L. (2010) Power, Conflict, and Cooperation: The Impact of guanxi in a Chinese Marketing Channel. Industrial Marketing Management, 39, 137-149. http://dx.doi.org/10.1016/j.indmarman.2008.07.002

[29] Zhuang, G.J. and Zhou, N. (2004) The Relationship between Power and Dependence in Marketing Channels: A Chinese Perspective. European Journal of Marketing, 38, 675-693. http://dx.doi.org/10.1108/03090560410529286

[30] Annamma, J. (2001) Gift Giving in Hong Kong and the Continuum of Social Ties. Journal of Consumer Research, 28, 239-256. http://dx.doi.org/10.1086/322900

[31] He, J.X. and Lu, T.H. (2007) Consumer-Brand Relationships in the Context of Chinese Culture: Theoretical Construct and Emprical Study. Journal of Business Economics, 11, 41-49.

[32] Arthur, A., Elaine, A.N., Michael, T. and Greg, N. (1991) Close Relationships as Including Other in the Self-Construal. Journal of Personality and Social Psychology, 60, 241-253. http://dx.doi.org/10.1037/0022-3514.60.2.241

[33] Leff, B., Herd, K.B. and Moreau, P.C. (2010) For You or for Me? How the Intended Recipient Influences the Customization Experience and Valuations of Customized Products. Journal of Marketing Research, 38, 1-47.

[34] Singelis, T.M. (1994) The Measurement of Independent and Interdependent Self. Personality and Social Psychology Bulletin, 20, 580-591. http://dx.doi.org/10.1177/0146167294205014

[35] Torelli, C.J. (2006) Individuality or Conformity? The Effect of Independent and Interdependent Self-Concepts on Public Judgments. Journal of Consumer Psychology, 16, 240-248. http://dx.doi.org/10.1207/s15327663jcp1603 6

[36] Zhang, Y.X. (2011) A Study of Influence of Face Concept on Social Gift Giving in China. Thesis, Shanghai Jiao Tong University, Shanghai.

[37] Cao, Y. and Fu, G.Q. (2012) Consumer Evaluations of Brand Extensions: The Influences of Brand User Image. Chinese Journal of Management, 723-728.

[38] Zhang, C., Zhang, T. and Zhuang, G.J. (2012) Impacts of Channel Tie Strength on the Channel Power Exercises from the Perspective of Relational Embeddedness. Journal of Managment Science, 3, 56-68.

[39] Dong, W.W. and Zhuang, G.J. (2013) From Interpersonal guanxi to Interorganizational Cooperation Relationship: The Moderating Effect of Renqing. Forecasting, 32, 17-22.

[40] Maheswaran, A. (2005) The Effects of Self-Construal and Commitment on Persuasion. Journal of Consumer Research, 31, 841-849. http://dx.doi.org/10.1086/426620

[41] Dodds, W.B., Monroe, K.B. and Grewal, D. (1991) Effects of Price, Brand, and Store Information on Buyers' Product Evaluations. Journal of Marketing Research, 28, 307-319. http://dx.doi.org/10.2307/3172866

[42] Chai, J.W., Zhao, G.Z. and Zhang, Z.L. (2011) Impact of Self Concept on the Effectiveness of Different Nostalgia Appeals. Acta Psychologica Sinica, 43, 308-321. http://dx.doi.org/10.3724/SP.J.1041.2011.00308

[43] Aaker, J.L. and Lee, A.Y.I. (2001) Seek Pleasures and We Avoid Pains: The Role of Self-Regulatory Goals in Information Processing and Persuasion. Journal of Consumer Research, 28, 33-49. http://dx.doi.org/10.1086/321946 


\section{Submit or recommend next manuscript to SCIRP and we will provide best service for you:}

Accepting pre-submission inquiries through Email, Facebook, LinkedIn, Twitter, etc.

A wide selection of journals (inclusive of 9 subjects, more than 200 journals)

Providing 24-hour high-quality service

User-friendly online submission system

Fair and swift peer-review system

Efficient typesetting and proofreading procedure

Display of the result of downloads and visits, as well as the number of cited articles

Maximum dissemination of your research work

Submit your manuscript at: http://papersubmission.scirp.org/ 